\title{
Factors contributing to teenage pregnancy in the Capricorn district of the Limpopo Province
}

\author{
Authors: \\ Tebogo M. Mothiba ${ }^{1}$ \\ Maria S. Maputle ${ }^{2}$ \\ Affiliations: \\ ${ }^{1}$ Department of Nursing, \\ University of Limpopo \\ (Turfloop campus), \\ South Africa \\ ${ }^{2}$ Department of Advanced \\ Nursing Science, University \\ of Venda, South Africa \\ Correspondence to: \\ Tebogo Mothiba \\ Email: \\ mariatm@ul.ac.za \\ Postal adress: \\ Private Bag X1106, Sovenga \\ 0727, South Africa

\section{Dates:} \\ Received: 18 July 2011 \\ Accepted: 17 Apr. 2012 \\ Published: 11 July 2012 \\ How to cite this article: \\ Mothiba, T.M. \& Maputle, \\ MS., 2012, 'Factors \\ contributing to teenage \\ pregnancy in the Capricorn \\ district of the Limpopo \\ Province', Curationis 35(1), \\ Art. \#19, 5 pages. http:// \\ dx.doi.org/10.4102/ \\ curationis.v35i1.19
}

C 2012. The Authors. Licensee: AOSIS OpenJournals. This work is licensed under the Creative Commons Attribution License.
Teenage pregnancy refers to pregnancy of a woman of less than 19 years. It is found commonly amongst young people who have been disadvantaged and have poor expectations with regard to either their education or job market. Adolescents may lack knowledge of access to conventional methods of preventing pregnancy, as they may be afraid to seek such information. The study purpose was to identify factors contributing to teenage pregnancy in one village in the Capricorn District of the Limpopo Province.

A quantitative descriptive research approach was chosen. Population consisted of all pregnant teenagers attending antenatal care during June to August 2007 at one clinic in the Capricorn District of the Limpopo Province. Simple random probability sampling was used to include 100 pregnant teenagers who satisfied the inclusion criteria. Data were collected through structured self-administered questionnaires. Descriptive statistical data analysis was used. Ethical considerations were ensured.

Findings were classified as demographic data where $24 \%$ of the respondents were aged between $15-16$ years and $76 \%$ were aged between $17-19$ years. Findings further revealed that $60 \%$ of the respondents started to engage in sex at $13-15$ years; $48 \%$ of the teenagers' partners were 21 years and above, $44 \%$ depended on a single parents' income; $20 \%$ father's income, $16 \%$ received a social grant and $8 \%$ lived on the pension fund of the grandparents.

Pregnancy prevention strategies were recommended based on the results. The strategies focused on reproductive health services, male involvement and adult-teenager communication programmes.

\section{Introduction}

\section{Problem statement}

The Limpopo Province is one of nine provinces of the Republic of South Africa and is situated in the far northern part of the country, its capital city is Polokwane. The province is divided into five districts namely: Vhembe, Mopani, Capricorn, Waterberg and Sekhukhuni. The study was conducted in the Capricorn District which is central to the entire districts and it has urban, semiurban and rural communities.

Despite the extensive attention given to adolescent sexuality and teenage pregnancy in the past 30 years, many teenagers were still falling pregnant (Van Eijk 2007). Teenage pregnancy has become a national epidemic, partly because more and more teenagers who give birth decide to keep and raise their children. There is a great cost to individuals, families and society when mere children have children of their own. Mwaba (2000) indicated that teenage pregnancy is more common amongst young people who have been disadvantaged and have poor expectations of either their education or the job market. The alarming figures released by Morake (2011) for the South African Provincial Education Department indicate that schoolgirl pregnancies have doubled in the past year, despite a decade of spending on sex education and Human Immunodeficiency Virus (HIV) and AIDS awareness. Premature sexual intercourse results in high rates of sexually transmitted diseases, HIV transmission, adolescent pregnancy and abortions (Mkhwanazi 2006).

Unprotected sexual intercourse can lead to an unwanted adolescent pregnancy which is often considered a serious social and public health problem. Teenagers have a high risk of unintended pregnancy (Mestad et al. 2011). Richter and Mlambo (2005) said teenage pregnancy appears to be encouraged by lack of access to sex education. Some parents are reluctant to make sex education and contraceptives available to their teenagers, as they are afraid that their teenagers might interpret this as permission to engage in sexual activities. They further pointed out that teenagers are reluctant to visit clinics to obtain contraceptives and thus do not make use of available health 
services. Morake (2011) revealed that teenagers appear to be ignorant about issues such as puberty, pregnancy and contraception. Ignorance, aggravated by cultural taboos to discuss sex with one's parents, combined with real or perceived peer group pressure to engage in sexual activities, cause unnecessary heartache for many young women. The study by Davies et al. (2006) indicated that the use of contraceptives has increased amongst adolescents in recent years. Whereas Manlove, Terry, Gitelson, Pappilo and Russel (2000) said that the consistent reliance on effective forms of contraception remains low. Reasons for inconsistent contraceptive use are not easily characterised as they are diverse and complex (Davies et al. 2006). Understanding teenage pregnancy involves recognising the complexities surrounding teenagers' attitudes and knowledge about the use of contraceptives (Phipps et al. 2008). Knowledge on sexual and reproductive issues amongst teenagers in Sekhukhune and Waterberg districts of Limpopo Province is low Morake (2011). There is also a lot of misinformation on sexual and reproductive issues that affect teenagers.

Most adolescents lack information on sexuality and contraception, as most of the education that is presented on this matter is limited (Arai 2003; Bankole, Ahmed, Ouedraogo, Neema \& Konyani 2007). The study by Kaufman, De Wet and Stadler (2001) indicated that there was a slightly lower level of knowledge about modern methods of contraception amongst teenagers. The authors further reported that young mothers in Soweto, South Africa, did not have knowledge of sexuality and information on contraception and contraceptive use. Morake (2011) indicated that in the reports of the Department of Health of the Limpopo Province, adolescents were reportedly not good contraceptive users, because they might not admit to being sexually active. Other studies reported that adolescents had inaccurate knowledge on the use of contraceptive (Bankole et al. 2007).

It implies that supplying adequate information about sexual behaviours and contraceptives to teenagers should be of paramount importance. Van Eijk (2007) outlines that even though a large number of teenage girls aged between 15-19 reported knowledge about methods of family planning, contraceptive use is low. Kaufman, De Wet and Stadler (2001) pointed out that amongst other barriers, clinic staff disapproves of teenagers being sexually active; ignorance about reproduction; misunderstanding by young people; and false assumptions and ignorance surrounding reproduction. Teenagers believe that pregnancy cannot result from the initial act of intercourse, but only by repeated sexual encounters. Teenagers are further surrounded by sexual images and messages, which imply that sexual activity is the norm (Mwaba 2000). High teenage pregnancy rates seem to exist in the Capricorn District of the Limpopo Province and this was also mentioned by Morake (2011) who indicated that statistics reflect that four out of ten girls fall pregnant at least once before they reach the age of 20. Yet some parents, and many public institutions, are at best either embarrassed about dealing with young people's sexuality or try to ignore it completely. This leads to the situation where it seems as if sex is compulsory amongst teenagers without giving due consideration that they should reach maturity age before engaging in sexual intercourse. It is against this background that the study on factors that contribute to teenage pregnancies was conducted in one village of the Capricorn District in the Limpopo Province.

\section{Purpose of the study}

The purpose of this study was to identify factors that contribute to teenage pregnancy in one village of the Capricorn District in the Limpopo Province.

The following research questions were used to guide the study:

- Which factors contribute to teenage pregnancy in one village of Capricorn District in the Limpopo Province?

- Are there any pregnancy prevention strategies available within the community at this village of the Capricorn District in Limpopo Province?

\section{Objectives of the study}

The objectives and the specific aims of this study were to:

- explore and describe the factors contributing to teenage pregnancy in the Capricorn district of the Limpopo Province and

- propose recommendations to strengthen pregnancy prevention strategies that are relevant to the needs of the community of this village in the Capricorn District of the Limpopo Province.

\section{Definition of concepts}

Teenager: A teenager is an individual in the transitional stage of development between childhood and full adulthood, representing the period of time during which a person is biologically adult but emotionally not fully matured (South African Concise Oxford Dictionary 2005). In this study, a teenager is a female person aged between 13-19 years.

Pregnancy: Pregnancy is the state in which a foetus develops in the uterus of a woman of childbearing age, during the period from conception to birth (South African Concise Oxford Dictionary 2005).

In the context of this study, pregnancy refers to a period of gestation when a woman aged between 13-19 years has conceived an unplanned foetus in her uterus.

\section{Significance of study}

It is anticipated that the study would contribute to the prevention of teenage pregnancies. The guidelines could be used in health care facilities to educate teenagers how to avoid unwanted pregnancies. 


\section{Research method and design Design}

A quantitative research approach was chosen for this study because it emphasises objectivity and uses systematic procedures to measure human behaviour by using formal structured instruments when collecting data from respondents (Brink 2006). This approach has been used to provide hard objective facts about factors that contribute to teenage pregnancy that could be statistically analysed and interpreted. In this study an attempt was made to obtain information from pregnant teenagers and to identify human behaviour that contributes to teenage pregnancy in one village in the Capricorn District of the Limpopo Province.

The descriptive design was selected as it is concerned with gathering more information about the phenomenon studied. This research design was suitable to obtain relevant information and to describe and identify factors that contribute to teenage pregnancy in one village in the Capricorn District of the Limpopo Province (Brink 2006).

\section{Population and Sampling}

The study population consisted of 103 pregnant teenagers attending antenatal care during the last weeks of June, July and August 2007 at one clinic in the Capricorn District of the Limpopo Province. Probability, simple random sampling was used to ensure that all subjects had an equal chance of being included in the study. The fish bowl technique was used to select the subjects randomly. At the clinic, random sampling with replacement was conducted as follows:

- One-hundred-and-three pieces of paper of which 3 were blank and 100 numbered 1 to 100 were placed in a box.

- The 100 respondents who picked numbered papers all voluntarily agreed to participate in the study (Brink 2006).

\section{Sample size}

The sample consisted of 100 pregnant teenagers who satisfied the inclusion criteria, their ages ranging between 13-19 years and who picked a paper with a number during the simple random probability sampling were included in the study.

\section{Data collection methods}

Data were collected through structured self-administered questionnaires. The questionnaires consisted of 23 questions that were divided into three parts namely, demographic data, factors that contribute to teenage pregnancy and sexual behaviour. The statements in the questionnaires were constructed to obtain objective data from the respondents who had met the inclusion criteria (De Vos, Strydom, Fouché \& Delport 2006). The questionnaire was formulated in English and translated into the local language (SePedi) by the lecturer who facilitates Translation Studies at the University of Limpopo, Turfloop Campus, School of Languages. The process was followed by the researchers to ensure authenticity of the data collection instrument to collect data, which would achieve the objectives of this study and further facilitate understanding during completion of the questionnaires by the respondents. The researcher handdelivered the questionnaires to those pregnant teenagers who consented to participate. Throughout the time when the participants were completing the questionnaires, the researchers were present either to clarify misunderstanding or to answer any questions (De Vos et al. 2006).

\section{Data analysis}

Descriptive statistical analysis was used, which included a frequency distribution table and percentages of respondents according to the selected characteristics (Brink 2006). The descriptive statistics and frequency distribution table were used and these assisted the researchers in the arrangement of the lowest to the highest scores linked with the number of times the score occurred. Each score was listed separately which means that the results were subdivided into classes, collection of scores and percentages of those scores which were grouped together, including demographic data, factors leading to sexual encounters and factors that contributed to teenage pregnancy (Brink 2006).

\section{Ethical considerations}

Ethical standards were based on the Democratic Nurses Association of South Africa (DENOSA) Ethical Standards for Nurse Researchers (Democratic Nurses Association of South Africa 1998). The quality of the research was ensured by adhering to the highest possible standards of research through accountability and the ability to execute the research process.

Permission to sample the pregnant teenagers was obtained from the clinic supervisor and Primary Health Care district manager. Each pregnant teenager was provided with sufficient and understandable information regarding her participation in the study before signing the consent form. For minors between 13-17 years of age, consent forms were signed by their parents or guardians. Confidentiality and anonymity were ensured by protecting the participants' identity, privacy, self worth and dignity by not indicating the subjects' names on the questionnaires.

\section{Validity and reliability}

Validity was ensured through probability, simple random sampling and ensuring that every member of the population had an equal chance of inclusion in the study. The researchers guaranteed that the sampling method could be applied repeatedly to the same respondents and would yield the same results (Brink 2006; De Vos et al. 2006; Babbie \& Mouton 2009).

\section{Discussions of results} Demographic data

One hundred ( $n=100)$ pregnant teenagers (between 13 and 19) who were attending antenatal care at one clinic in the 
Capricorn District of the Limpopo Province participated voluntarily in the study. Twenty-four per cent $(24 \%)$ of the respondents were aged between 15-16 years, whilst $76 \%$ were between the ages of 17 years and 19 years.

According to the Department of Health (2009) prevalence of contraceptive use is the lowest amongst women in their late twenties through to their thirties. The study results reflected that $10 \%$ of the participants were married whilst $90 \%$ of the participants were single during their teenage years when they became pregnant.

\section{Age of first engagement in sexual intercourse}

Sixty-two per cent (62\%) of the respondents started engaging in sexual activities between the age of 13 years and 15 years; $54 \%$ engaged for the first time in sexual intercourse between the age of between 16 years 19 years whilst $4 \%$ started at the age of 10-12 years. This is supported by Cooper et al. (2004) who found that amongst teenage girls interviewed in South Africa, 35\% were teenagers aged 19 years of which $53 \%$ of the pregnancies had either been unplanned at $36 \%$ or unwanted at $17 \%$. In addition Morake (2011) revealed that the age of the first pregnancies - as a result of the first sexual intercourse - was experienced by teenagers between the age of 13 years and 16 years.

\section{Age of partners}

Forty-eight per cent (48\%) of the respondents had partners who were 21 years and above; $43 \%$ had partners between 19-20 years and 9\% had partners between $16-18$ years. The vast majority of teenagers became pregnant by partners who were older than they were. According to Morake (2011) intergenerational relationship was found to be low amongst teenage mothers. Mwaba (2000) disagreed, indicating that the pressure by older boys and their refusal to use condoms during sexual intercourse, were the main reasons for teenage pregnancies.

\section{Socio-economic status}

Forty-four per cent (44\%) of participants depended on their single mother's income, others worked as domestic workers; $20 \%$ depended on a father's income and $12 \%$ depended on the income of both parents. Sixteen per cent $(16 \%)$ of participants received a child support grant and $8 \%$ lived from pension fund payments. It was evident from the study findings that most pregnant teenagers depended on a single mother's income. Van Eijk (2007) indicated that teenagers from lower income families are more likely to report having sexual intercourse regardless of the family structure or race. It is further pointed out that teenagers from single parent family homes are more likely to report having sexual intercourse regardless of the income of the family.

In support of the study findings Van Eijk (2007) indicated that the widespread belief that young women are having children specifically so they could access a grant is unfounded because the teenagers in this study who were pregnant and were receiving a child support grant were few as indicated above.

\section{Factors contributing to teenage pregnancy}

Several factors are strongly associated with and contribute to the increased risk of an early pregnancy. These factors include: lack of knowledge about sex and how to use contraceptives; barriers to access contraceptives including negative attitudes of health staff; peer pressure; sexual coercion; low self-esteem; low educational expectations; poverty; family breakdown; and heightened sex-based messages in the media.

Most respondents in this study had knowledge about the use of contraceptives and other ways of preventing unwanted pregnancy apart from total abstinence from sexual activity. The results revealed that $88 \%$ of participants were knowledgeable about the use of contraceptives and $12 \%$ not. Those who were knowledgeable about contraceptives chose not to use them or keep the use of any contraceptives a secret. Other reasons for not utilising the contraceptives were that teenagers were reluctant to take contraceptive precautions for fear of complications and parental detection, despite their knowledge about the importance of the use of those contraceptives (Ritcher \& Mlambo 2005). The findings by Ritcher and Mlambo (2005) outlined that teenage pregnancies resulted from lack of knowledge about contraception and many other misconceptions. It was indicated that injectable contraceptives cause weight gain and watery discharges, whilst contraceptive pills were only taken when they planed sexual intercourse or only after the engagement because it could prevent them from becoming pregnant when used in that way. In a study by Mwaba (2000) teenage girls expressed a preference for receiving the injectable contraceptive and stated that condoms were not their birth control method of choice. Respondents further mentioned that teenage boys did not visit family planning clinics and were reluctant to use condoms as a form of contraceptive and a method of infection control. The teenage boys refused to use condoms because they commented that sex with a condom was not enjoyable.

\section{Factors leading to sexual encounter}

Drug usage: The study findings pointed out that $96 \%$ of the respondents didn't use drugs, 4\% did smoke, and 92\% didn't drink alcohol whereas 8\% drank alcohol. In support of the study findings Van Eijk (2007) indicated that substance abuse was long recognised as one of the greatest health and social problems in South Africa which resulted in teenage pregnancies because teenagers engaged in sexual intercourse without making calculated decisions due to the influence of alcohol. Additionally it was outlined that drinking became more common as young people moved through their teenage years rising to $45 \%$ amongst 15 year olds and this was proven to be a cause of teenage pregnancies.

\section{Limitations of the study}

The study results are limited to one village in the Capricorn District and will not be generalised to all villages in the district. It is suggested that the same study be conducted in other villages in order to determine the factors which contribute to teenage pregnancies amongst the teenagers who attend the clinics for antenatal care. 


\section{Recommendations}

The factors driving teenage pregnancy are complex and varied and therefore require multifaceted intervention strategies. There is a wide variety of strategies aimed at preventing adolescent pregnancy including education programmes, family planning services, school-based health centres, youth-friendly clinics and youth development programmes. The following pregnancy prevention strategies are recommended based on the results of this study:

- Develop more effective preventive measures for teenage pregnancy and have solutions that might prevent unplanned teenage pregnancy.

- Pregnancy prevention programmes with guidelines should be available and utilised appropriately in all areas where teenagers are found.

- Teenagers should be offered information on how to use contraceptives. Contraceptive use should be promoted through education and service provision to reduce teenage pregnancy.

- Public clinics should all be made 'youth-friendly' through existing support programmes. These programmes have been proven to improve the quality of care and expand access to contraceptives, support and counselling. There should be increased access to dual method contraception at clinics and contraception should be available to all girls and young women who need it.

- Increase awareness and knowledge about and availability of emergency hormonal contraception; since this safe, effective and reliable method of post-coital contraception is paramount to tackle the unplanned pregnancy rates.

- Facilitate the establishment of adult-teenage communication programmes with guidelines to give adults information and skills to communicate effectively with young people about reducing risky behaviour.

- Facilitate the establishment of male involvement programmes for prevention efforts that specifically target boys and young men. Effective programmes for boys include programmes such as community service or other out-of-school activities with a cultural component. Boys and young men have information needs and anxieties about sex and relationships.

\section{Conclusion}

The increase in the number of teenage pregnancies is causing great concern and is becoming a critical issue. This situation requires the urgent attention of every section of society in order to prevent family life from disintegrating completely.

\section{Acknowledgements}

The researchers would like to acknowledge the clinic supervisor and the district manager for having allowed them to conduct the research in the clinic.

\section{Competing interests}

The authors of this article declare that they had no financial or personal relationship(s) which had inappropriately influenced them in writing this article.

\section{Authors' contributions}

T.M.M. (University of Limpopo) was responsible for requesting permission to collect data and the scheduling of appointments with the respondents in order to collect data through structured self-administered questionnaires and handed over the questionnaires to the respondents. Furthermore both T.M.M and M.S.M. (University of Venda) analysed the data and worked together to compile the report. T.M.M. was responsible to compile the final report for submission to Curationis.

\section{References}

Arai, L., 2003, 'Low expectations, sexual attitudes and knowledge: Explaining teenage pregnancy and fertility in English communities. Insights from qualitative research', The Sociological Review 51, 199-217. http://dx.doi.org/10.1111/1467954X.00415

Babbie, E. \& Mouton, J., 2009. The practice of Social Research. Oxford University Press, Cape Town.

Bankole, A., Ahmed, F. H., Ouedraogo, C., Neema, S., \& Konyani, S., 2007, 'Knowledge of correct condom use and consistency of use among adolescents in four
countries in Sub-Saharan Africa.' African Journal of Reproductive Health 11, 198countries in Sub-Saharan Africa.' African Journal of Reproductive Health 11, 198-
220. http://dx.doi.org/10.2307/25549740, PMid:18458741, PMCid:2367135

Brink, H.I., 2006, Fundamentals of Research Methodology for Health Care Professionals, 2nd edn., Juta, Cape Town.

Cooper, D., Morroni, C., Orner, P., Moodley, J., Harries, J., Cullingworth, L. \& Hoffman, M., 2004, 'Ten years of Democracy in South Africa: Documenting Transformation in Reproductive Health Policy and Status', Reproductive Health Matters Journal 12(24), 70-85. http://dx.doi.org/10.1016/S0968-8080(04)24143-X

Davies, S.L., DiClemente, R.J., Wingood, G.M., Person, S.D., Dix, D.P., Harrington, K., Crosby, R.A. \& Oh, K., 2006, 'Predictors of inconsistent contraceptive use K., Crosby, R.A. \& Oh, K., 2006, 'Predictors of inconsistent contraceptive use
among adolescent girls: Findings from prospective study', Journal of Adolescent among adolescent girls: Findings from prospective study', Journal of Adolescent
Health 38(1), 43-49. http://dx.doi.org/10.1016/j.jadohealth.2005.10.011, Health 38(1), 43-49. http://dx.doi.org/10.1016/j.jadohealth.2005.10.011
PMid:16781960

Democratic Nurses Organization of South Africa (DENOSA), 1998, Ethical Standards for Nurse Researchers, DENOSA, Pretoria.

Department of Health, 2009, Family Planning Method and Practice, Government Printers Africa, Pretoria.

De Vos, A.S., 1998, Research at Grass Roots, Van Schaik, Pretoria.

De Vos, A.S., Strydom, H., Fouché, C.B., \& Delport, C.S.L., 2006, Research at Grass roots for the Social Sciences and Human Service Professions, 3rd edn., J.L. van Schaik Academic, Pretoria.

Kaufman, C.E., De Wet, T. \& Stadler, J., 2001, Adolescent pregnancy and parenthood in Limpopo Department of Health 2011. Factors associated with Teenage Pregnancy in Limpopo Province, Government Printer, Polokwane.

Manlove, J., Terry, E., Gitelson, L., Pappilo, A.R. \& Russel, S., 2000, 'Explaining demographic trends in teenage fertility', Family Planning Perspective 32(4), 166175. http://dx.doi.org/10.2307/2648233, PMid:10942352

Mestad, R., Secura, G., Allsworth, J.E., Madden, T., Zhao, Q. \& Pelpert, J.F., 2011 Acceptance of long-acting reversible contraceptive methods by adolescents participants in the contraceptive CHOICE Project, Contraception 84(5), 493-498.

Mkhwanazi, N., 2006, 'Teenage pregnancy and gender identities in the making in a post apartheid South African township', PhD dissertation, Department of Anthropology, University of Cambridge.

Morake, A., 2011, Factors associated with Teenage Pregnancy in Limpopo Province. Government Printers, Polokwane.

Mwaba, K., 2000, 'Perceptions of teenage pregnancy among South African adolescents', Health SA Gesondheid 5(3), 30-35.

Nash, E.S., 1990, 'Teenage pregnancy - need a child bear a child?', South African Medical Journal 77, 147-51, PMid:2406956

Okonofua, F.E., 1995, 'Factors associated with adolescent pregnancy in rural Nigeria', Journal of Youth and Adolescence 24(4), 419-435. http://dx.doi.org/10.1007/ BF01537189,PMid:12319941

Phipps, M.G., Rosengard, C., Weitzen, S., Meers, A. \& Billikoff, Z., 2008, 'Age group differences among pregnant adolescent sexual behaviour, health habits and contraceptive use, Journal of Paediatric and Adolsecent Gynecology 21(1), 9-15. http://dx.doi.org/10.1016/j.jpag.2007.07.009, PMid:18312794

Ritcher, M.S. \& Mlambo, G.T., 2005, 'Perceptions of rural teenagers on teenage pregnancy', Health SA Gesondheid 10(2), 61-69.

South African Oxford School Dictionary, 2007, Oxford University Press Southern Africa, Cape Town.

South Africa, Studies in family Planning 32(2), 147-160.

Van Eijk, R.T., 2007, Factors contributing to teenage pregnancies in Rarotonga, United Nations Population Fund (UNFPA), Avarua. 